\title{
Cation control on the synthesis of $p$-t-butylthiacalix[4](bis)crown ethers
}

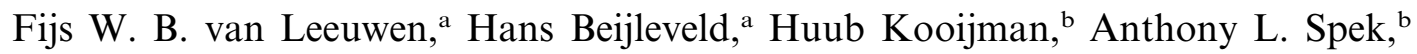 \\ Willem Verboom ${ }^{\mathrm{a}, *}$ and David N. Reinhoudt ${ }^{\mathrm{a}, *}$ \\ ${ }^{a}$ Laboratory of Supramolecular Chemistry and Technology, Mesa ${ }^{+}$Research Institute, University of Twente, PO Box 217, \\ 7500 AE Enschede, The Netherlands \\ ${ }^{\mathrm{b}}$ Bijvoet Center for Biomolecular Research, Crystal and Structural Chemistry, Utrecht University, Padualaan 8, \\ 3584 CH Utrecht, The Netherlands
}

Received 20 August 2002; revised 9 October 2002; accepted 18 October 2002

\begin{abstract}
Bridging of $p$ - $t$-butylthiacalix[4]arene with ethylene glycol ditosylates gave diametrically bridged thiacalix[4]monocrowns-4 and -5, 1,2-alternate thiacalix[4]biscrowns-4 and -5 and 1,3-alternate thiacalix[4]biscrown-5, dependent on the metal carbonate used. They show excellent extraction ability towards $\mathrm{Ag}^{+}$cations. C 2002 Elsevier Science Ltd. All rights reserved.
\end{abstract}

In the past we have shown that diametrically bridged calix[4]crowns are excellent ionophores for alkali metal cations such as $\mathrm{K}^{+}$and $\mathrm{Cs}^{+}$, depending on the conformation and crown ether bridge. ${ }^{1,2}$ Proximally bridged calix[4]crowns have been obtained, but only in relatively low yield $(<40 \%) .{ }^{3,4}$ Thiacalix[4]arene is an interesting novel member of the calixarene family., Unsubstituted thiacalix[4]arene is able to complex various transition metals, due to the presence of the bridging sulfur atoms. ${ }^{7}$ The participation of sulfur in the complexation has been observed in X-ray crystal structures of complexes with alkali metal cations. ${ }^{8}$ The complexation properties of thiacalix[4]arenes can be altered, both by functionalizing the lower rim with ligating sites or by oxidation of the bridging sulfur atoms. ${ }^{9-12}$ The groups of Vicens ${ }^{13}$ and Bitter ${ }^{14}$ have reported the synthesis of the diametrically substituted thiacalix[4]biscrowns-5 and -6. To the best of our knowledge only two proximally bridged thiacalix[4]crowns have been reported; a cyclic phosphorous diester amide and a lactone. ${ }^{15-17}$ In this communication we present our preliminary results of a systematic study on thiacalix[4](bis)crown formation using ethylene glycols of varying chain lengths and

Keywords: thiacalix[4]arene; crown ether; extraction; monovalent cations.

* Corresponding author. Tel.: +31(0)53 4892977; fax: +31(0)53 4894645; e-mail: w.verboom@ct.utwente.nl different metal carbonates. With different metal carbonates different products were obtained. The 1,2-alternate thiacalix[4]biscrowns $\mathbf{4}$ and $\mathbf{5}$ were obtained under mild conditions.

The reactions of thiacalix[4]arene ${ }^{18} \mathbf{1}$ with tri- or tetraethylene glycol ditosylates $\mathbf{2}$ and $\mathbf{3}$ in acetonitrile were systematically studied by varying the metal carbonate, reaction time, etc. ${ }^{19}$

With 4 equiv. of $\mathrm{Cs}_{2} \mathrm{CO}_{3}$ after $6 \mathrm{~h}$, reaction of 1 with $\mathbf{2}$ (1.8 equiv.) exclusively afforded the 1,2-alternate thiacalix[4]biscrown-4 4 in $72 \%$ yield upon precipitation of the crude reaction mixture with methanol/acetone. Also the reaction of 1 and 3 (1.8 equiv.) with 4 equiv. of base gave a fast reaction $(12 \mathrm{~h}, 100 \%$ conversion). The reaction gave a mixture of the 1,2-alternate thiacalix[4]biscrown-5 5 and the corresponding 1,3-alternate isomer 6. The pure thiacalix[4]biscrown-5 isomers $5(27 \%)$ and $6(15 \%)$ were isolated by fractional precipitation from methanol/acetone mixtures. Surprisingly, the proximal thiacalix[4]biscrowns-4 and -5 were only obtained in the 1,2-alternate conformation. The corresponding proximally substituted thiacalix[4]monocrown and proximally substituted cone thiacalix[4]biscrown compounds could not be detected. Compounds $\mathbf{4}$ and $\mathbf{5}$ were characterized by NMR $\left({ }^{1} \mathrm{H}\right.$ and $\left.{ }^{13} \mathrm{C}\right)$ and MS. ${ }^{20,21}$ Definite proof for the 1,2-alternate thiacalix[4]biscrown55 was obtained by an X-ray crystal structure (Fig. 1). ${ }^{22}$ 

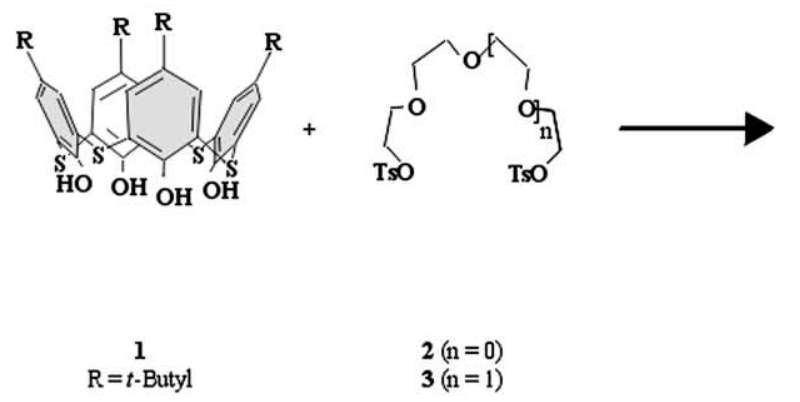

$2(\mathrm{n}=0)$

$3(n=1)$
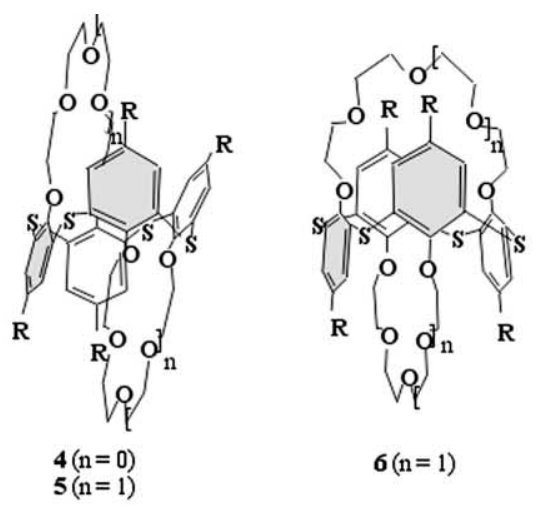

$6(n=1)$

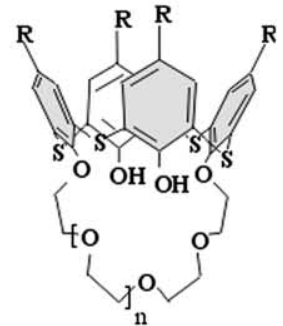

$7(n=0)$

$8(\mathrm{n}=1)$

Scheme 1.

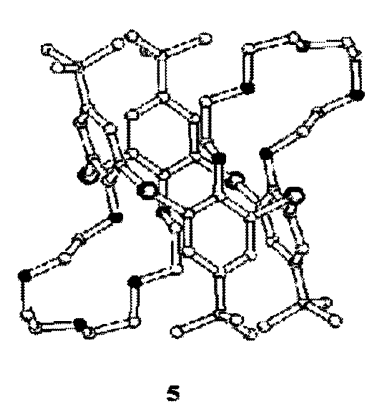

Figure 1. X-Ray crystal structures of 5 and 6. Hydrogen atoms and the minor disorder component were omitted for clarity.

The reaction between $\mathbf{1}$ and $\mathbf{2}$ (1.8 equiv.), using $\mathrm{K}_{2} \mathrm{CO}_{3}$, gave only minor conversion to 1,2-alternate thiacalix[4]biscrown-4 4. Apparently, in this case the 1,3-alternate thiacalix[4]biscrown-4 was not formed. With 4 equiv. of $\mathrm{K}_{2} \mathrm{CO}_{3}$, the reaction between 1 and 3 (1.8 equiv.) exclusively gave the 1,3-alternate thiacalix[4]biscrown-5 $6^{23}(12 \mathrm{~h}, 100 \%$ conversion) in $74 \%$ yield after precipitation of the crude reaction mixture from methanol/acetone. The 1,3-alternate conformation clearly followed from its X-ray crystal structure (Fig. $1)^{22}$

Reaction of 1 and 2 (1 equiv.) with $\mathrm{Na}_{2} \mathrm{CO}_{3}$ (12 equiv.) gave the diametrically bridged thiacalix[4]crown-4 7 (15 d, 50\% conversion). Separation of 7 from 1 and $\mathbf{2}$ was not possible. Reaction of 1 and 3 (1 equiv., 12 equiv. of $\left.\mathrm{Na}_{2} \mathrm{CO}_{3}\right)$ gave thiacalix[4]crown-5 8 (11 d, 50\% conversion). ${ }^{24}$ Column chromatography $\left(\mathrm{CH}_{2} \mathrm{Cl}_{2} / \mathrm{MeOH}\right)$ afforded $\mathbf{8}$ in $20 \%$ yield, based on reacted thiacalix[4]arene 1 (Scheme 1).

Recently, Miyano et al. reported the $\mathrm{p} K_{\mathrm{a}}$ values of sulfonated thiacalix[4]arene in water to be 2.18, 8.45, 11.61 , and $11.99 .^{25}$ The relatively small difference between the second and the third and fourth $\mathrm{p} K_{\mathrm{a}}$ values may explain the relatively easy formation of thiacalix[4]biscrowns. We found that with $\mathrm{Na}_{2} \mathrm{CO}_{3}$ only diametrically bridged thiacalix[4]monocrown products were obtained. Both $\mathrm{K}_{2} \mathrm{CO}_{3}$ and $\mathrm{Cs}_{2} \mathrm{CO}_{3}$ afforded thiacalix[4]biscrowns. Probably, the softer $\mathrm{Cs}^{+}$ions ${ }^{26}$ interact with the sulfur atoms favoring the formation of the 1,2-alternate biscrowns 4 and 5. Apparently, the formation of the second bridge is so fast that the proximally substituted thiacalix[4]monocrowns cannot be isolated. Reaction of 1 with 3 in the presence of 4 equiv. of $\mathrm{Cs}_{2} \mathrm{CO}_{3}$ and an excess of $\mathrm{KClO}_{4}$ exclusively gave the 1,3-alternate thiacalix[4]biscrown-5 6, which is otherwise obtained using $\mathrm{K}_{2} \mathrm{CO}_{3}$ as base. This demonstrates the influence of the cation on the outcome of the reaction.

The conformational difference observed in the crystal structures of the two isomers 5 and $\mathbf{6}$ (Fig. 1) is also reflected in the ${ }^{1} \mathrm{H}$ NMR spectra. 1,3-Alternate thiacalix[4]biscrown-5 6 has a $C_{2}$ symmetry axis and two planes of symmetry through the thiacalix[4]arene annulus. As a consequence both the aromatic and $t$-butyl hydrogens appear as one signal in the ${ }^{1} \mathrm{H}$ NMR spectrum at 7.34 and $1.36 \mathrm{ppm}$, respectively. ${ }^{14} 1,2-$ Alternate thiacalix[4]biscrown-5 5 has, in addition to an inversion point, a plane of symmetry and a $C_{2}$ axis resulting in two signals for the Ar-H's (7.72 and 7.56 ppm), whereas the $t$-butyl groups appear as one peak (1.37 ppm), because they are equivalent. In 5 the hydrogen atoms of the methylene groups that are connected to the phenolic oxygens appear to be diastereotopic as reflected in the double triplets observed at $4.23(4 \mathrm{H})$ and $3.10(4 \mathrm{H}) \mathrm{ppm}$ in the ${ }^{1} \mathrm{H}$ NMR spectrum (Fig. 3).

Extraction experiments, with various monovalent metal ions, were performed according to the Cram picrate extraction method; ${ }^{27}$ the results are summarized in Fig. 2 .

The diametrically bridged monocrown 8 and the 1,2alternate biscrowns $\mathbf{4}$ and $\mathbf{5}$ showed an excellent (90$100 \%$ ) extraction of $\mathrm{Ag}^{+}$ions. Lamartine et al. reported that thiacalix[4]arene $\mathbf{1}$ only gave 7\% extraction of $\mathrm{Ag}^{+}$ ions. $^{28} \mathrm{CPK}$ molecular models suggest that both the sulfur atoms and the bridging ethylene glycol units participate in the complexation. For the latter this is clearly proven by significant shifts in the ${ }^{1} \mathrm{H}$ NMR spectra induced upon complexation of $\mathbf{5}$ and $\mathbf{8}$ with Ag-picrate (Fig. 3). 


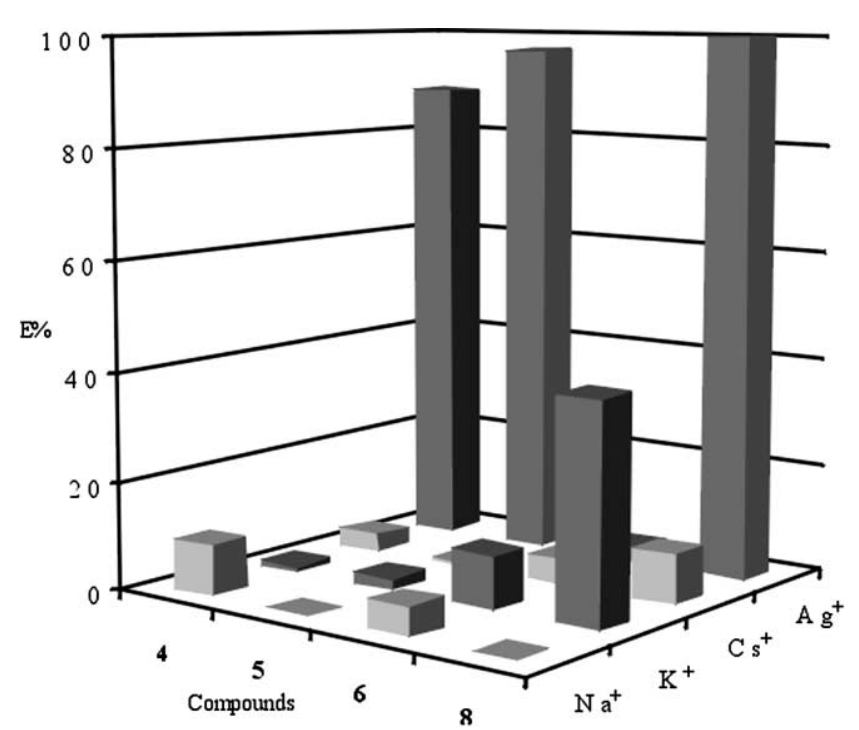

Figure 2. Extraction results of compounds 4, 5, 6 and 8, $[\mathrm{L}]=2.5 \times 10^{-3} \mathrm{M}$ in chloroform $(1 \mathrm{~mL}),[\mathrm{MPic}]=2.5 \times 10^{-4} \mathrm{M}$ with $0.1 \mathrm{M} \mathrm{MOH}\left(\mathrm{M}=\mathrm{Na}, \mathrm{K}, \mathrm{Cs}\right.$ or $[\mathrm{LiPic}]=2.5 \times 10^{-4} \mathrm{M}$ with $0.1 \mathrm{M} \mathrm{AgNO}_{3}$ in water $(1 \mathrm{~mL})$.

Participation of the sulfur atoms has recently been suggested for the $\mathrm{Ag}^{+}$-complexation of 1,2-alternate tetrakis[(2-pyridylmethyl)oxy]-thiacalix[4]arene by Yamamoto et al. ${ }^{29}$ Despite the presence of sulfur atoms 1,3-alternate thiacalix[4]biscrown-5 $\mathbf{6}$ hardly extracted any $\mathrm{Ag}^{+}$ions $(3 \%)$. This may be due to the fact that in 6 co-operation between the ethylene glycol bridge and the bridging sulfur atoms is not possible as followed from CPK molecular models and the X-ray crystal structure (Fig. 1).

The extraction of $\mathrm{K}^{+}(40 \%)$ and $\mathrm{Cs}^{+}(10 \%)$ by the diametrical thiacalix[4]monocrown-5 8 is in agreement

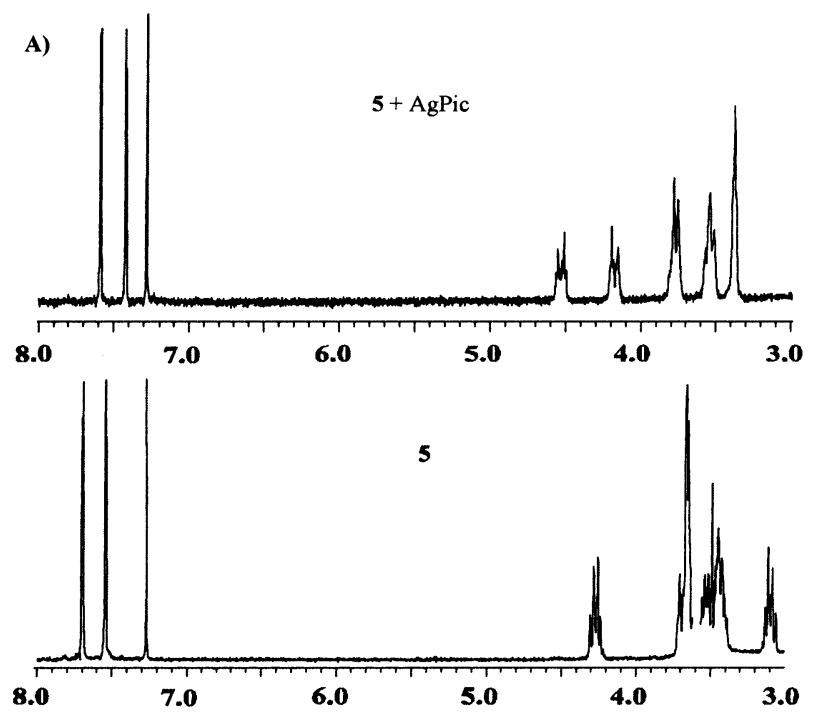

with the selectivity found for calix[4]crown-5. ${ }^{1}$ Ligands 4,5 , and 6 exhibited only a marginal ability to extract alkali metal ions. The low extraction percentages found for 6 , e.g. $\mathrm{K}^{+}(10 \%)$ compared to $8(40 \%)$, is caused by the steric hindrance of the $t$-butyl groups in the 1,3alternate conformation as was already reported by Grün et al. ${ }^{14}$

\section{Acknowledgements}

This research is supported by the Technology Foundation STW, applied science division of NWO and the technology programme of the Ministry of Economic Affairs.

\section{References}

1. Casnati, A.; Pochini, A.; Ungaro, R.; Ugozzoli, F.; Arnaud, F.; Fanni, S.; Schwing, M. J.; Egberink, R. J. M.; de Jong, F.; Reinhoudt, D. N. J. Am. Chem. Soc. 1995, 117, 2767-2777.

2. Casnati, A.; Pochini, A.; Ungaro, R.; Bocchi, C.; Ugozzoli, F.; Egberink, R. J. M.; Struijk, H.; Lugtenberg, R.; de Jong, F.; Reinhoudt, D. N. Chem. Eur. J. 1996, 2, 182-191.

3. Arduini, A.; Domiano, L.; Pochini, A.; Secchi, A.; Ungaro, R.; Ugozzoli, F.; Struck, O.; Verboom, W.; Reinhoudt, D. N. Tetrahedron 1997, 53, 3767-3776.

4. Mathieu, A.; Asfari, Z.; Vicens, J. Tetrahedron Lett. 2002, 43, 1225-1229.

5. Hosseini, M. W. In Calixarenes: Asfari, Z.; Böhmer, V.; Harrowfield, J.; Vicens, J., Eds. Thia-, mercapto-, and thiamercapto-calix[4]arenes. Kluwer Academic Publishers: Dordrecht, The Netherlands, 2001, pp. 110-129.

6. Iki, N.; Miyano, S. J. Incl. Phenom. 2001, 41, 99-105.

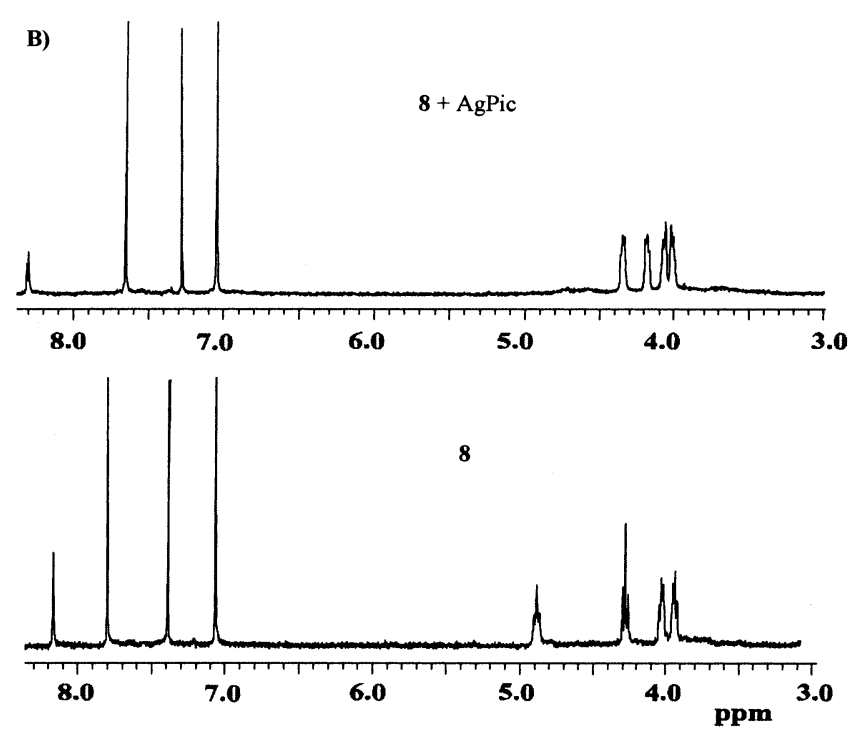

Figure 3. (A) ${ }^{1} \mathrm{H}$ NMR spectrum of compound 5 with and without AgPic. (B) ${ }^{1} \mathrm{H}$ NMR spectrum of compound 8 with and without AgPic. The peak at $7.28 \mathrm{ppm}$ belongs to $\mathrm{CDCl}_{3}$; the $t$-Bu and picrate peaks are omitted as no shifts were observed upon complexation. 
7. Morohashi, N.; Iki, N.; Sugawara, A.; Miyano, S. Tetrahedron 2001, 57, 5557-5563.

8. Bilyk, A.; Hall, A. K.; Harrowfield, J. M.; Hosseini, M. W.; Skelton, B. W.; White, A. H. Inorg. Chem. 2001, 40, 672-686.

9. Akdas, H.; Mislin, G.; Graf, E.; Hosseini, M. W.; De Cain, A.; Fischer, J. Tetrahedron Lett. 1999, 40, 21132116.

10. Lhoták, P.; Kaplánek, L.; Stibor, I.; Lang, J.; Dvoráková, H.; Hrabal, R.; Sýkora, J. Tetrahedon Lett. 2000, 41, 9339-9344.

11. Iki, N.; Kumagai, H.; Morhashi, N.; Ejima, K.; Hasewaga, M.; Miyanari, S.; Miyano, S. Tetrahedron Lett. 1998, 39, 7559-7562.

12. Mathieu, A.; Asfari, Z.; Thuéry, P.; Nierlich, M.; Faure, S.; Vicens, J. J. Incl. Phenom. 2001, 40, 173-181.

13. Lamare, V.; Dozol, J. F.; Thuéry, P.; Nierlich, M.; Asfari, Z.; Vicens, J. J. Chem. Soc., Perkin Trans. 22001 , 1920-1926.

14. Grün, A.; Csokai, V.; Parlagh, G.; Bitter, I. Tetrahedron Lett. 2002, 43, 4153-4156.

15. Lhoták, P.; Dudicč, M.; Stibor, I.; Petřičková, H.; Sýkora, J.; Hodačová, J. Chem. Commun. 2001, 731-732.

16. Weber, D.; Gruner, M.; Stoikov, I. I.; Antipin, I. S.; Habicher, W. D. J. Chem. Soc., Perkin Trans. 22000 , 1741-1744.

17. Just before submission of this manuscript a paper appeared describing an indirect route to the synthesis of proximally bridged thiacalix[4]arene monocrowns: Narumi, F.; Masumura, N.; Morohashi, N.; Kameyama, H.; Miyano, S. J. Chem. Soc., Perkin Trans. 1 2002, 1843-1844.

18. Kumagai, H.; Hasegawa, M.; Miyanari, S.; Sugawa, Y.; Sato, Y.; Hori, T.; Ueda, S.; Kamiyama, H.; Miyano, S. Tetrahedron Lett. 1997, 38, 3971-3972.

19. General procedure: To a $0.02 \mathrm{M}$ solution of $1 \mathrm{mmol}$ of $p$ - $t$-butylthiacalix[4]arene $\mathbf{1}$ in $\mathrm{CH}_{3} \mathrm{CN}$ were added base and $(n)$ ethylene glycol ditosylate $(n=3,4)$. The solution was refluxed under argon. Subsequently, the solvent was evaporated and dichloromethane was added (for the reaction mixtures containing 1,2-alternate thiacalix[4]biscrowns chloroform was used). The solution was washed twice with $10 \% \mathrm{HCl}$ and once with water and evaporated to dryness, whereupon, the crude reaction mixture was purified further. Differences between conversions and isolated yields are mainly due to the separation methods used.

20. Compound 4: ${ }^{1} \mathrm{H}$ NMR $\delta 7.77(\mathrm{~d}, 4 \mathrm{H}, J=2.6 \mathrm{~Hz}), 7.52$ $(\mathrm{d}, 4 \mathrm{H}, J=2.6 \mathrm{~Hz}), 4.06(\mathrm{~m}, 4 \mathrm{H}), 3.85(\mathrm{~m}, 4 \mathrm{H}), 3.45(\mathrm{~m}$, $12 \mathrm{H}), 3.23(\mathrm{~m}, 4 \mathrm{H}), 1.37(\mathrm{~s}, 36 \mathrm{H}) ;{ }^{13} \mathrm{C}$ NMR $\delta 157.2$, $145.9,133.9,129.4,129.4,128.2,71.9,69.6,68.4,33.9$, 30.9; MS $m / z 971\left(100 \%,[\mathrm{M}+\mathrm{Na}]^{+}\right)$. Anal. calcd for
$\mathrm{C}_{52} \mathrm{H}_{68} \mathrm{O}_{8} \mathrm{~S}_{4} \cdot 0.2 \mathrm{CHCl}_{3}$ : C, 64.41; H, 7.06. Found: C, $64.18 ; \mathrm{H}, 6.73$.

21. Compound 5: ${ }^{1} \mathrm{H}$ NMR $\delta 7.72(\mathrm{~d}, 4 \mathrm{H}, J=2.4 \mathrm{~Hz}), 7.56$ $(\mathrm{d}, 4 \mathrm{H}, J=2.4 \mathrm{~Hz}), 4.25(\mathrm{t}, 2 \mathrm{H}, J=6.9 \mathrm{~Hz}), 4.22(\mathrm{t}, 2 \mathrm{H}$, $J=5.9 \mathrm{~Hz}), 3.35-3.70(\mathrm{~m}, 24 \mathrm{H}), 3.12(\mathrm{t}, 2 \mathrm{H}, J=6.2 \mathrm{~Hz})$, $3.09(\mathrm{t}, 2 \mathrm{H}, J=6.4 \mathrm{~Hz}), 1.37(\mathrm{~s}, 36 \mathrm{H}) ;{ }^{13} \mathrm{C}$ NMR $\delta 156.8$, $145.6,133.8,130.3,128.8,128.4,71.2,70.9,69.8,68.9$, 33.9, 30.9; MS $m / z 1037.5\left(100 \%,[\mathrm{M}+\mathrm{H}]^{+}\right)$. Anal. calcd for $\mathrm{C}_{56} \mathrm{H}_{76} \mathrm{O}_{10} \mathrm{~S}_{4}$ : C, 64.83; $\mathrm{H}, 7.38$. Found: $\mathrm{C}, 64.78 ; \mathrm{H}$, 7.38.

22. Crystal data were measured at $150 \mathrm{~K}$ on a Nonius KappaCCD diffractometer $\left(\lambda_{\mathrm{Mo} \mathrm{K} \alpha}=0.71073 \AA\right)$. Structures were solved using direct methods (SHELXS-86) and refined on $F^{2}$ (SHELXL-97). Crystal data for 5: triclinic, space group $P \overline{1}$ (no. 2) with $a=10.4720(10), \quad b=$ $11.2486(15), \quad c=11.4484(15) \quad \AA, \quad \alpha=88.533(10), \quad \beta=$ 84.495(10), $\gamma=84.610(10)^{\circ}, V=1336.2(3) \AA^{3}, Z=1,6070$ independent reflections, 319 parameters, $\mathrm{w} R_{2}=0.155$, $R_{1}=0.055$ (for $\left.4526 I>2 \sigma(I)\right) S=1.05$. Crystal data for 6 : orthorhombic, space group $\mathrm{Pbca}$ (no. 61) with $a=$ 16.7260(10), $\quad b=17.4914(10), \quad c=38.238(2) \quad \AA, \quad V=$ $11187.0(11) \AA^{3}, Z=8,10221$ independent reflections, 632 parameters, $w R_{2}=0.130, R_{1}=0.052$ (for $7795 I>2 \sigma(I)$ ) $S=1.01$.

Crystallographic data (excluding structure factors) for the structures in this paper, have been deposited with the Cambridge Crystallographic Data Centre as supplementary publication numbers CCDC 190662 (compound 5) and CCDC 190663 (compound 6). Copies of the data can be obtained, free of charge, on application to CCDC, 12 Union Road, Cambridge CB2 1EZ, UK (fax: +44(0)1223-336033 or e-mail: deposit@ccdc.cam.ac.uk).

23. For the spectroscopic data see Ref. 14. In our case a $30 \%$ higher yield was obtained.

24. Compound 8: ${ }^{1} \mathrm{H}$ NMR $\delta 8.06(\mathrm{~s}, 2 \mathrm{H}), 7.68(\mathrm{~s}, 4 \mathrm{H}), 6.94$ $(\mathrm{s}, 4 \mathrm{H}), 4.78(\mathrm{t}, 4 \mathrm{H}, J=5.5 \mathrm{~Hz}), 4.17(\mathrm{t}, 4 \mathrm{H}, J=5.7 \mathrm{~Hz})$, $3.91(\mathrm{~m}, 4 \mathrm{H}), 3.82(\mathrm{~m}, 4 \mathrm{H}), 1.37(\mathrm{~s}, 18 \mathrm{H}), 0.82(\mathrm{~s}, 18 \mathrm{H})$; ${ }^{13} \mathrm{C}$ NMR $\delta 155.5,147.4,134.1,132.2,128.6,121.6,72.5$, 70.3, 70.0, 69.2, 33.7, 33.5, 30.6, 30.2; MS $m / z 901(100 \%$, $\left.[\mathrm{M}+\mathrm{Na}]^{+}\right)$. Anal. calcd for $\mathrm{C}_{48} \mathrm{H}_{62} \mathrm{O}_{7} \mathrm{~S}_{4} \cdot 0.7 \mathrm{H}_{2} \mathrm{O}: \mathrm{C}, 64.67$; H, 7.16. Found: C, 64.49; H, 7.04.

25. Matsumiya, H.; Terazono, Y.; Iki, N.; Miyano, S. J. Chem. Soc., Perkin Trans. 2 2002, 1166-1172.

26. Pearson, R. G. Hard and Soft Acids and Bases; Dowden, Hutchkinson \& Ross: Stroudsburg, Pennsylvania, 1973.

27. Moore, S. S.; Tarnowski, T. L.; Newcomb, M.; Cram, D. J. J. Am. Chem. Soc. 1977, 99, 6398-6410.

28. Lamartine, R.; Bavoux, C.; Vocanson, F.; Martin, A.; Senlis, G.; Perrin, M. Tetrahedron Lett. 2001, 42, 10211024.

29. Yamato, T.; Zhang, F.; Kumamaru, K.; Yamamoto, H. J. Incl. Phenom. 2002, 42, 51-60. 